\title{
An Improbable Case of Ascites
}

\author{
Virginia Visconti, Andre Fernandes, Ismenia Oliveira \\ Internal Medicine Department, Beatriz Ângelo Hospital, Loures, Portugal
}

Received: 07/01/2020

Accepted: $16 / 01 / 2020$

Published: $22 / 12 / 2020$

How to cite this article:Visconti V, Fernandes A, Oliveira I. An improbable case of ascites. EJCRIM 2020;7: doi:10.12890/2020_001474.

Conflicts of Interests: The Authors declare that there are no competing interests.

This article is licensed under a Commons Attribution Non-Commercial 4.0 License

\section{ABSTRACT}

Prostate cancer is the most frequent malignancy seen in males, with about $15 \%$ of cases showing metastatic disease at diagnosis, most commonly in bones (vertebrae, ribs, long bones). However, peritoneal metastasis with malignant ascites is extremely rare and may be overlooked by physicians. We report the case of a 77-year-old man presenting with symptoms of abdominal distension, nausea and weight loss. Abdominal ultrasound and computerised tomography confirmed ascites, peritoneal carcinomatosis and an enlarged prostate. Serum and ascitic prostatic-specific antigen were both elevated. Prostate biopsy identified a prostate adenocarcinoma, while biopsy of a peritoneal implant identified a prostate cancer metastasis, which responded well to hormonal therapy.

\section{LEARNING POINTS}

- Prostate cancer is the most frequent malignancy found in men, often metastasising to bones and lymph nodes.

- Although a rare site of metastasis, peritoneal cancer should be suspected when encountering a case of malignant ascites, in order to not delay diagnosis and treatment.

- Despite the generally poor prognosis of this malignancy, early diagnosis and hormonal treatment may lead to good clinical, symptomatic and analytical outcomes.

\section{KEYWORDS}

Prostate cancer, peritoneum, peritoneal metastasis, malignant ascites

\section{INTRODUCTION}

Ascites is the accumulation of fluid within the peritoneal cavity. Despite varying causes, around 80\% are associated with portal hypertension, secondary to hepatic cirrhosis. Other aetiologies include congestive heart failure and malignancies (such as ovarian cancer or mesothelioma). However, ascites associated with prostate cancer is very rare and only a few cases have been published to date ${ }^{[1]}$. Prostate cancer generally metastasises to bone, lung, liver or pleura and less frequently to skin, salivary glands, the thyroid, testicles and pituitary glands. The peritoneum, however, is an extremely rare metastatic site ${ }^{[2]}$.

\section{CASE DESCRIPTION}

We present the case of a 77-year-old man with a prior history of essential arterial hypertension and benign prostatic hyperplasia, treated accordingly with amlodipine, lisinopril and tamsulosin. He was admitted to the internal medicine department following a gastroenterology consultation due to a progressive increase in abdominal volume, nausea, anorexia, fatigue and a $5 \%$ unintentional total weight loss over the previous month. He presented with no lower urinary tract symptoms, altered bowel movements, visible blood loss or relevant epidemiological context. 
He appeared alert, cooperative, haemodynamically stable, eupnoeic at rest, afebrile, with a distended abdomen, grade 2 ascites and signs of collateral circulation. A hard enlarged prostate was found on rectal examination. No peripheral oedema was observed.

Laboratory tests showed haemoglobin of $13.7 \mathrm{~g} / \mathrm{dL}$, with no leukocytosis or thrombocytopenia. There was normal renal and hepatic function, with no electrolyte abnormalities. Reactive C-protein was $0.73 \mathrm{mg} / \mathrm{dL}$. Malignancy work-up examinations were negative, apart from an elevated prostate-specific antigen (PSA) of $584.8 \mathrm{ng} / \mathrm{mL}$. Upper endoscopy and colonoscopy showed no abnormalities.

An abdominal ultrasound and a full body computerised tomography were performed showing a normal sized liver, with dense-looking free intraperitoneal liquid and peritoneal carcinomatosis, as well as a heterogenous, enlarged prostate. A diagnostic and therapeutic paracentesis was performed, draining $3 \mathrm{~L}$ of murky yellowish fluid, with a serum-ascites albumin gradient of over $1.1 \mathrm{~g} / \mathrm{dL}$, leucocytes $970 /$ $\mu \mathrm{L}(6 \%$ polymorphonuclear) and a PSA level of $2,212 \mathrm{ng} / \mathrm{mL}$.

The patient then underwent a guided prostatic biopsy that revealed a prostatic adenocarcinoma, Gleason score 9 , as well as a guided biopsy of a peritoneal implant, compatible with prostate carcinoma metastasis. Bone scintigraphy showed metastatic bone lesions on the left femoral trochanter.

As a result, a diagnosis of stage IV prostate cancer (peritoneal carcinomatosis and bone metastasis) was made. The patient began a complete androgen blockage with bicalutamide, combined with a luteinising hormone-releasing hormone agonist. Within 3 months of treatment, the PSA had reduced to $4 \mathrm{ng} / \mathrm{mL}$, with substantial clinical benefit and reduced abdominal volume.

\section{DISCUSSION}

Prostate cancer is the most frequent malignancy seen in men, representing the second most common cause of death by cancer in this gender. Both during the initial diagnosis and the disease progression, the cancer can metastasise to various organs, most commonly bones and lymph nodes. The association of prostate cancer and malignant ascites is very rare and of poor prognosis [3]; hence, physicians should be aware of this complication in order to not delay diagnosis and treatment ${ }^{[4]}$. In patients with ascites, where prostate disease is being considered, PSA immunohistostaining of the ascitic fluid can be an important diagnostic tool ${ }^{[5]}$.

\section{REFERENCES}

1. Ani I, Costaldi M, Abouassaly R. Metastatic prostate cancer with malignant ascites: a case report and literature review. Can Urol Assoc J 2013;7(3-4):e248-e250. Saif MW. Malignant ascites associated with carcinoma of the prostate. J Appl Res 2005;5(2):305-311.

3. Saif MW, Figg WD, Hewitt S, Brosky K, Reed E, Dahut W. Malignant ascites as only manifestation of metastatic prostate cancer. Prostate Cancer Prostatic Dis 1999;2;290-293.

4. Petrakis D, Pentheroudakis G, Kamina S, Pappa L, Papadiotis E, Malamou-Mitsi V, et al. An unusual presentation of a patient with advanced prostate cancer, massive ascites and peritoneal metastasis: case report and literature review. J Adv Res 2015;6(3)517-521.

5. Saini R, Dodagoudar C, Talwar V, Singh S. Malignant ascites with omental metastasis: a rare event in prostate cancer. J Cancer Metastasis Treat 2015;1:34-35. 